\title{
Internet Of Things-Based Orchid Plant Watering Tool
}

\section{Alat Penyiraman Tanaman Anggrek Berbasis Internet Of Things}

\author{
Irwan Solikudin $^{1}$, Syamsudduha Syahrorini ${ }^{2}$ \\ \{ irwansolikudin@gmail.com¹, syahrorini@umsida.ac.id ${ }^{2}$ \} \\ Program Studi Teknik Elektro, Universitas Muhammadiyah Sidoarjo ${ }^{1}$, Program Studi Teknik Elektro, Universitas \\ Muhammadiyah Sidoarjo ${ }^{2}$
}

\begin{abstract}
The orchid flower is an ornamental plant that has a lot of interest. For orchid cultivation, there are many things that need to be monitored, including the watering process. Referring to this, an Internet of Things (IoT) based orchid watering device was made which uses Arduino as a microcontroller, the yl-69 sensor as a soil moisture reader, the DHT11 sensor as a temperature reader, the float swith sensor as an automatic reservoir and an omron timer as a timer for administration. vitamin. All data read by the sensor is sent to the Thingspeak webserver and forwarded to the MIT App Invertor application installed on the smartphone. This tool is made to make it easier for a cultivator to monitor watering plants remotely via an application on a smartphone. After taking data for about two weeks, the sensor readings were obtained, including the yl-69 sensor in wet conditions which has a standard deviation of 0.89 and dry conditions 1.18, the DHT11 sensor has a standard deviation of 0.4 for temperature. For the development of orchid plants, it shows quite good results, it is shown from the stems and leaves of the plants that begin to elongate and grow thick.
\end{abstract}

Keywords: The orchid flower, Thingspeak, MIT App Inventor

Abstrak.Bunga anggrek merupakan tanaman hias banyak sekali peminatnya. Untuk pembudidayaan anggrek banyak sekali hal yang perlu dipantau diantaranya pada proses penyiramannya. Mengacu pada hal tersebut dibuatlah alat penyiraman tanaman anggrek berbasis Internet Of Things (IoT) yang memanfaatkan arduino sebagai mikrokontroler, sensor yl-69 sebagai pembaca kelembaban tanah, sensor DHT11 sebagai pembaca suhu, sensor float swith sebagai otomatis tandon dan timer omron sebagai pengatur waktu pemberian vitamin. Semua data yang dibaca oleh sensor dikirimkan ke webserver thingspeak dan diteruskan ke aplikasi MIT App Invertor yang terinstal pada smartphone. Alat ini dibuat agar memudahkan seorang pembudidaya dalam memonitoring penyiraman tanaman dari jarak jauh melalui aplikasi pada smartphone. Setelah dilakukan pengambilan data selama kurang lebih dua minggu didapatkan data pembacaan sensor antara lain sensor yl-69 pada kondisi basah mempunyai standart deviasi 0,89 dan kondisi kering 1,18, sensor DHT11 memiliki standart deviasi sebesar 0,4 untuk suhu. Untuk perkembangan tanaman anggrek menunjukkan hasil yang cukup baik hal itu ditunjukkan dari batang dan daun tanaman mulai memanjang dan lebat.

Kata kunci : Tanaman anggrek, Thingspeak, MIT App Inventor

\section{Pendahuluan}

Di era Globalisasi perkembangan teknologi sangatlah pesat, apalagi teknologi pada pertanian [1]. Berbagai macam sistem-sistem canggih untuk pertanian muncul akibat perkembangan teknologi ini [1] [2], beberapa diantaranya sistem kendali, sistem deteksi dan sistem monitoring. Untuk melakukan pembudidayaan tanaman anggrek ini banyak sekali aspek-aspek yang harus diperhatiakan mulai dari kelembaban tanah, suhu udara serta insentitas cahaya. Untuk mendapatkan hasil yang optimal dalam pembudiyaan anggrek ini harus memiliki kelembaban udara berkisar $60-85 \%$ serta suhu berkisar antara $25-35^{\circ} \mathrm{C}$ [3]. Untuk menunjang pertumbuhan tanaman diperlukan penambahan pupuk GROW QUICK $L B$, yang didalamnya mengandung vitamin B1 serta pemberian zat pengatur tumbuh benziladenin (BA). Benziladenin (BA) adalah zat untuk pengatur tumbuh sitokinin, fungsi sitokinin pada tumbuhan. [4] [5] Melihat kondisi diatas, Muncul sebuah ide untuk membuat suatu penelitian ini. Prinsip kerja dari Penelitian ini adalah melakukan penyiraman otomatis yang mengacu pada pembacaan kelembaban tanah pada sensor YL69 soil moisture serta memanfaatkan timer omron untuk melakukan pemberian vitamin secara otomatis, arduino uno sebagai microkontroler yang dikendalikan oleh aplikasi smartphone yaitu aplikasi MIT App invertoryang berbasis Internet Of Things, dengan sistem Internet of things penyiraman tanaman anggrek dapat dikendalikan dari jarak jauh dengan koneksi wifi. 


\section{Metodologi Penelitian}

Pada penelitian ini berfokus pada monitoring dan pengkontrolan alat penyiraman tanaman otomatis. Alat ini dapat membaca kelembaban tanah, suhu udara, ketinggian air pada tandon dan penghitung waktu untuk pemberian vitamin. Data pembacaan pada setiap sensor akan dikirimkan mickrokontroler Arduino uno dengan bantuan modul wifi esp 8266 menuju webserver thingspeak dan kemudian ditampilkan pada aplikasi yang sudah dibuat melalui software MIT App invertor.

Untuk komponen input pada penelitian ini menggunakan sensor yl-69 sebagai pembaca kelembaban tanah, sensor DHT11 sebagai pembaca suhu udara, sensor float swith sebagai otomatis tandon dan timer omron sebagai penghitung waktu penyiraman vitamin. Semua sensor tersebut menggerakkan masing-masing 1 output berupa pompa maupun kipas angin.

\section{A. Perancangan Sistem}

Pada perancangan sistem alat penyiraman tanaman anggrek berbasis internet of things (IoT) terdapat dua tahap perancangan yaitu perancangan software dan hardware. Untuk melihat alur dari semua sistem yang dirancang dapat dilihat pada diagram blok yang ditunjukkan oleh gambar 1 .

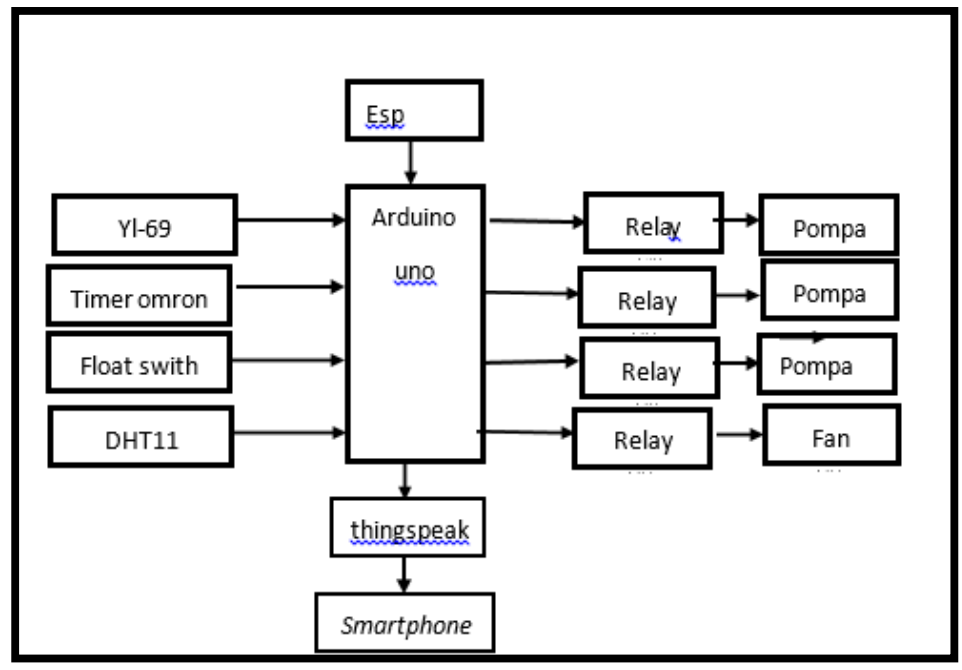

Gambar 1. Diagram Blok Sistem

\section{B. Perancangan Hardware}

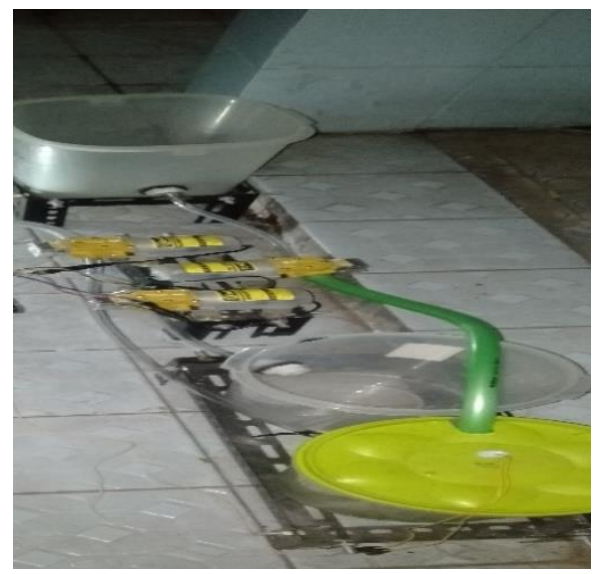

Gambar 2. Perancangan hardware

Pada gambar 2 menjelaskan tandon yang dibuat untuk tempat air dan tempat vitamin serta pompa air yang. Pangkon untuk tempat pompa air dan tandon menggunakan besi siku 4 inch, toples plastic 5 liter 3 buah sebagai tempat air utama, tempat air untuk penyiraman dan tempat vitamin tanaman, 3 buah pompa air digunakan untuk mengisi tandon penyiraman, menyiram tanaman dan untuk menyiramkan vitamin pada tanaman menggunakan 
Procedia of Engineering and Life Science Vol. 1. No. 1 March 2021

Seminar Nasional \& Call Paper Fakultas Sains dan Teknologi (SENASAINS 1st)

Universitas Muhammadiyah Sidoarjo

pompa merk shell yang mampu mempunyai max tekanan 130 psi dan pada sekitar tanaman terdapat fan pc yang berfungsi sebagai penyejuk tanaman jika suhu udara sekitar panas.

\section{Perancangan Software}

Pada perancangan software meliputi pembuatan flow chart terlebih dahulu agar mengetahui system kerja alat penyiraman tanaman anggrek berbasis internet of things $(I o T)$. Untuk gambar flow chart dapat dilihat pada gambar 3.

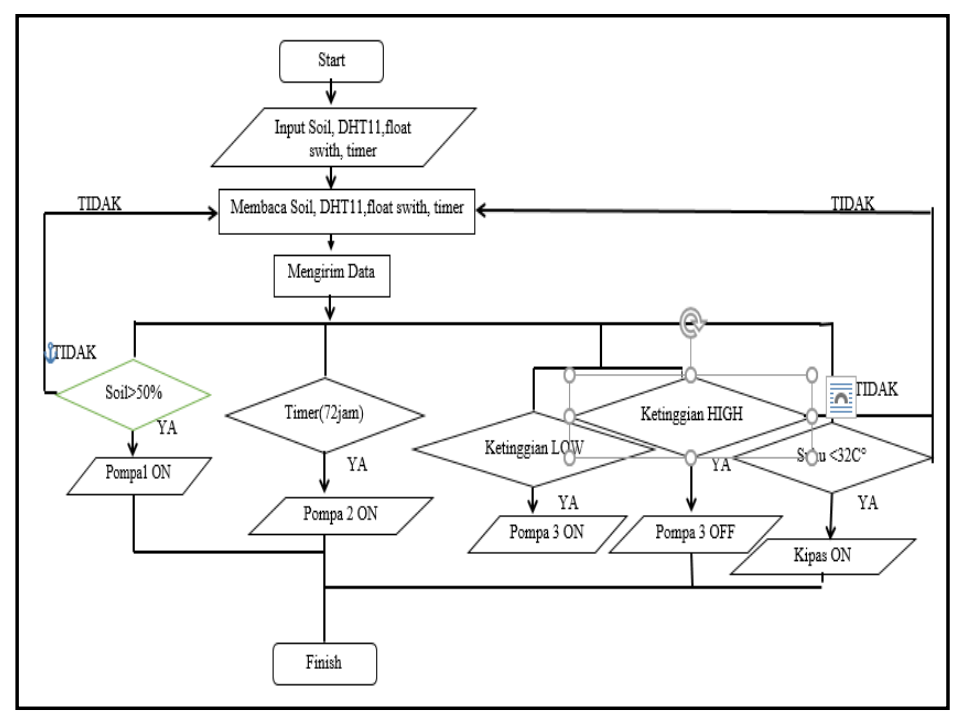

Gambar 3. Flowchart Sistem

Pada flowchart diatas berisi tentang alur kerja alat pemyiraman tanaman anggrek berbasis internet of things (IoT). Untuk menunjang kerja alat secara optimal dibutuhkan pembacaan sensor yang akurat, maka diperlukan percobaan sensor-sensor yang terpasang. Percobaan sensor-sensor dilakukan dengan mengambil data pembacaan sensor selama 5 kali, setelah itu dilakukan perhitungan untuk menentukan rata-rata pembacaan sensor serta standart deviasi setiap sensor. Nilai dari standart deviasi inilah yang menjadi acuan kepekaan pembacaan setiap sensor.dibawah ini ialah rumus untuk ,mmenentukan besarnya standart deviasi.

$\sigma=\sqrt{\frac{\sum_{i=1}^{n}\left(x_{i}-\mu\right)}{n-1}}$

Untuk membuat suatu balat penyiraman tanaman anggrek berbasis internet of things (IoT) dibutuhkan suatu software MIT App invertor. Software ini berguna untuk membuat suatu aplikasi yang dapat dipasang langsung pada smartphone, didalam MIT App invertor telah disediakan sarana untuk mendesain aplikasi sesuain dengan apa yang dibutuhkan oleh user. Untuk lebih jelasnya tampilan MIT App invertor dapat dilihat pada gambar 4.

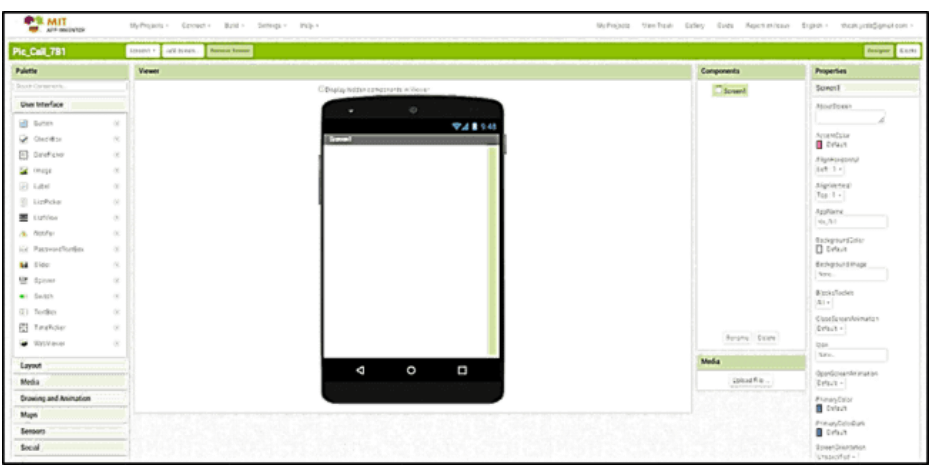

Gambar 4. MIT App Inventor

Dalam pembuatan alat penyiraman tanaman anggrek berbasis internet of things (IoT) juga diperlukan suatu webserver thingspeak sebagai tempat penerima data pembacaan sensor yang dikirimkan melalui mickrokontroler Arduino uno dengan bantuan modul wifi esp 8266. Data yang ditampilkan oleh webserver thingspeak berupa grafik dan bersifat real time sesuai dengan kodisi alatnya. Untuk lebih jelasnya dapat dilihat pada gambar 5. 
Procedia of Engineering and Life Science Vol. 1. No. 1 March 2021

Seminar Nasional \& Call Paper Fakultas Sains dan Teknologi (SENASAINS 1st)

Universitas Muhammadiyah Sidoarjo

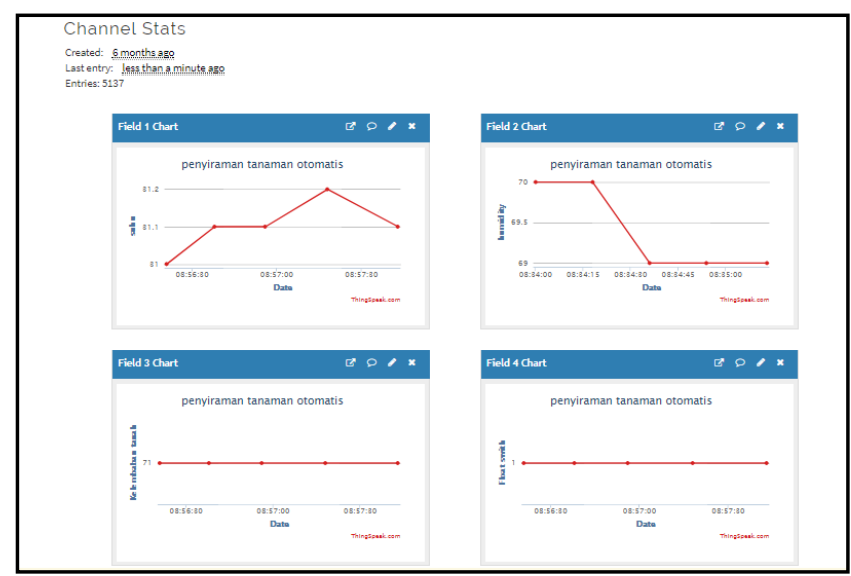

Gambar 5. Web Server thingspeak

\section{Hasil dan Pembahasan}

Pada bagian ini berisi tentang percobaan dan analisa pada sistem mulai dari percobaan setiap sistem sampai dengan percobaan secara keseluruhan.

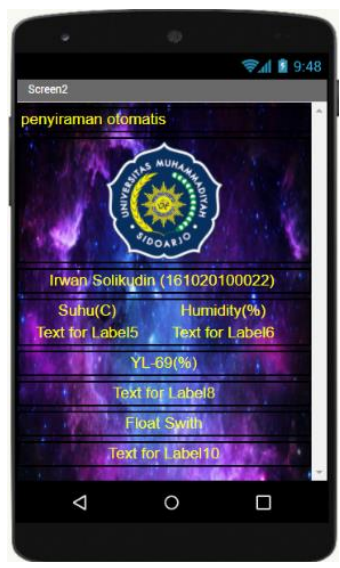

Gambar 6. Aplikasi MIT App Inventor Pada Smartphone

Aplikasi pada smartphone dibuat pada dengan software MIT App Invertor, data yang tampil pada aplikasi ini adalah data pembacaan sensor yang dikirimkan Arduino uno dengan bantuan modul wifi esp 8266 ke web server thingspeak. Pada web server thingspeak data setiap sensor ditampilkan dalam bentuk grafik. Untuk gambar pembacaan web server thingspeak dapat dilihat pada gambar 7 .

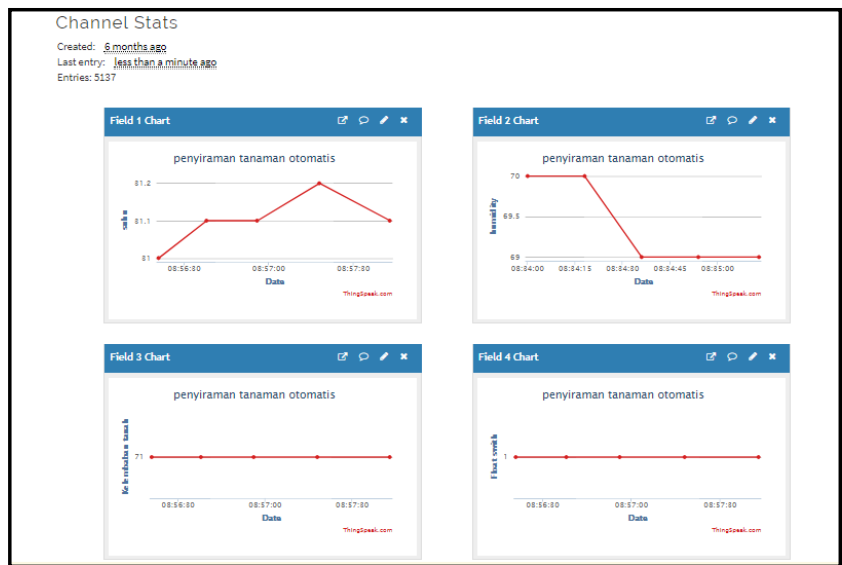

Gambar 7. Tampilan Chart Pada Web Server Thingspeak 


\section{A. Pengujian Yl-69}

Dalam percobaan sensor soil moisture yl-69 hal yang pertama dilakukan adalah merakit sensor soil moisture yl-69 dengan Arduino uno sesuai dengan spesifikasi yang ada pada sensor setelah itu baru diprogram menggunakan aplikasi Arduino ide. Dibawah ini adalah gambar percobaan sensor soil moisture dalam keadaan kering dan dalam keadaan basah.

\section{Tabel 1 Pengujian Sensor Yl-69}

\begin{tabular}{|c|c|c|c|c|c|}
\hline \multirow[t]{3}{*}{ No } & \multicolumn{3}{|c|}{ Sensor YL-69 } & \multirow{2}{*}{\multicolumn{2}{|c|}{$\begin{array}{l}\text { Standart } \\
\text { Deviasi }\end{array}$}} \\
\hline & \multirow{2}{*}{$\begin{array}{c}\text { Waktu } \\
\text { (min) }\end{array}$} & \multicolumn{2}{|c|}{$(\%)$} & & \\
\hline & & Basah & Kering & Basah & Kering \\
\hline 1 & $5 \mathrm{~min}$ & 77 & 31 & & \\
\hline 2 & $5 \mathrm{~min}$ & 77 & 31 & & \\
\hline 3 & $5 \mathrm{~min}$ & 76 & 30 & 0,8944 & 1,1832 \\
\hline 4 & $5 \mathrm{~min}$ & 77 & 30 & & \\
\hline 5 & $5 \mathrm{~min}$ & 77 & 31 & & \\
\hline Rat & a-Rata & 76,8 & 30,6 & & \\
\hline
\end{tabular}

Dari tabel diatas telah dilakukan percobaan pada sensor soil moisture dengan didiamkan pada tanah yang basah dan tanah yang kering dalam jangka waktu yang sudah ditentukan dan Data sensor diambil setiap 5 menit sekali. Setelah dilakukan percobaan telah didapatkan rata-rata pada percobaan tanah basah adalah 76,8 dan standart deviasi 0,8944. Ditinjau dari nilai standart deviasi dapat disimpulkan bahwa pembacaan sensor stabil. Pada percobaan tanah kering didapatkan rata-rata 30,6 dengan nilai standart deviasi 1,1832. Ditinjau dari nilai standart deviasi pembacaan sensor dapat dikatakan cukup stabil.

\section{B. Pengujian Sensor DHT11}

Dalam pengujian sensor DHT11 pertama-tama harus dihubungkan terlebih dahulu dengan Arduino. Pengawatan dengan Arduino sesuai dengan spesifikasi yang ada pada sensor DHT11.

\section{Tabel 2 Pengujian Sensor DHT11}

\begin{tabular}{cccccc} 
No & $\begin{array}{c}\text { Range } \\
\text { Waktu }\end{array}$ & $\begin{array}{c}\text { Suhu } \\
(\mathrm{c})\end{array}$ & $\begin{array}{c}\text { Hum } \\
(\%)\end{array}$ & Suhu & Hum \\
& & 52.2 & 59 & & \\
1 & $5 \mathrm{~min}$ & 32.2 & 58 & & \\
2 & $5 \mathrm{~min}$ & 32.2 & 58 & & \\
3 & $5 \mathrm{~min}$ & 32.4 & 58,2247 \\
4 & $5 \mathrm{~min}$ & 32.3 & 59 & 0,4 & $1,22$. \\
5 & 5 min & 32.2 & 57 & & \\
\multicolumn{2}{l}{ Rata-Rata } & 32.22 & 58.2 & &
\end{tabular}

Pada tabel diatas telah didapatkan data suhu dan humidity yang dibaca oleh sensor DHT11, setelah dilakukan pengambilan data selama 5 kali dapat diketahui rata-rata suhu yang dibaca adalah $32,22^{\circ} \mathrm{C}$ dengan standart deviasi 0,4 dan rata-rata humidity yang terbaca adalah 58,2 dengan standart deviasi 1,2247. Ditinjau dari standart deviasi suhu dan humidty dapat disimpulkan bahwa pembacaan suhu dan humidty dapat dikatakan stabil.

\section{Pengujian Sistem Secara Keseluruhan}

Pengujian secara keseluruhan dilakukan agar mengetahui alat bekerja secara optimal.

\section{Tabel 3 Pengujian Sistem Secara Keseluruhan}

\begin{tabular}{|c|c|c|c|c|c|c|c|c|c|c|}
\hline \multirow[b]{2}{*}{ NO } & \multicolumn{2}{|c|}{ DHT 11} & \multirow{2}{*}{ YL_69 } & \multirow{2}{*}{$\begin{array}{c}\text { Timer } \\
\text { Omron }\end{array}$} & \multirow{2}{*}{$\begin{array}{l}\text { Float } \\
\text { swith }\end{array}$} & \multicolumn{4}{|c|}{ Kondisi pompa } & \multirow{2}{*}{ Keterangan } \\
\hline & Suhu & Humidity & & & & $\mathrm{F} 1$ & $\mathrm{P} 2$ & P3 & P1 & \\
\hline 1 & 31 & 58 & 59 & 5 & 1 & Off & Off & Off & On & Normal \\
\hline 2 & 31 & 60 & 47 & 25 & 0 & Off & On & Off & Off & Normal \\
\hline
\end{tabular}


Procedia of Engineering and Life Science Vol. 1. No. 1 March 2021

Seminar Nasional \& Call Paper Fakultas Sains dan Teknologi (SENASAINS 1 ${ }^{\text {st }}$ )

Universitas Muhammadiyah Sidoarjo

$\begin{array}{ccccccccccc}3 & 33 & 68 & 73 & 72 & 0 & \text { On } & \text { Off } & \text { Off } & \text { Off } & \text { Normal } \\ & 33 & 65 & 70 & 1 & 0 & \text { On } & \text { Off } & \text { Off } & \text { Off } & \text { Normal } \\ 5 & 31 & 60 & 58 & 10 & 1 & \text { Off } & \text { Off } & \text { Off } & \text { On } & \text { Normal }\end{array}$

Pada hasil yang tertampil Tabel 3 menunjukan sistem secara keseluruhan pada perangkat telah beroperasional sesuai dengan desain yang telah direncanakan, prinsip kerja dapat terlihat dipenjelasan flowchart sistem pada Gambar 3.

\section{Perkembangan Tanaman Anggrek}

Untuk perkembangan tanaman anggrek dilakukan pengambilan data selama 3 hari sekali dan data diambil sebanyak 5 kali pengambilan.

$\begin{array}{ll}\text { No } & \text { Periode } \\ & \\ 1 & \text { Periode } 1 \\ 2 & \text { Periode } 2 \\ 3 & \text { periode } 3 \\ 4 & \text { Periode } 4 \\ 5 & \text { Periode } 5 \\ & \text { Rata-rata }\end{array}$

\begin{tabular}{cc}
\multicolumn{2}{c}{ anggrek 1 } \\
$\begin{array}{c}\text { Akar } \\
(\mathrm{cm})\end{array}$ & $\begin{array}{c}\text { Daun } \\
(\mathrm{cm})\end{array}$ \\
0,5 & 3 \\
1 & 5 \\
1.7 & 8 \\
2.1 & 9.5 \\
2.4 & 10.7 \\
0.42 & 1.74
\end{tabular}

$$
\begin{gathered}
\text { Perkembangan } \\
\text { Anggrek } 2
\end{gathered}
$$

$\begin{array}{cc}\begin{array}{c}\text { Batang } \\ (\mathrm{cm})\end{array} & \begin{array}{c}\text { Daun } \\ (\mathrm{cm})\end{array} \\ 2 & 2 \\ 4.5 & 3,5 \\ 6.5 & 5,2 \\ 7.8 & 6,1 \\ 9 & 7 \\ 1.6 & 1,2\end{array}$

\begin{tabular}{cc}
\multicolumn{2}{c}{ Anggrek 3 } \\
Akar & $\begin{array}{c}\text { Daun } \\
(\mathrm{cm})\end{array}$ \\
$(\mathrm{cm})$ & 2,5 \\
0.3 & 4 \\
0.9 & 5,3 \\
1.7 & 6 \\
2 & 7,9 \\
2.3 & 1,28 \\
0,42 &
\end{tabular}

Pada tabel merupakan data dari hasil pemantauan perkembangan tanaman anggrek selama 5 periode pengambilan, data yang diambil mulai dari perkembangan daun batang dan juga akar.

\section{KESIMPULAN}

Setelah dilakukan pengambilan data selama beberapa hari dapat disimpulkan bahwa alat penyiraman tanaman anggrek bebasis internet of things berjalan cukup baik. Hal ini ditunjukkan dari perkembangan tanaman anggrek yang cukup stabil mulai tanaman anggrek 1 sampai dengan tanaman anggrek 3 . Untuk penerapan system internet of things juga berjalan cukup efektif, hal ini ditunjukkan alat berjalan secara otomatis sesuai dengan pembacaan sensor yang terpasang serta penggunaan web server thingspeak berjalan cukup baik hal ini ditunjukkan dengan pembacaan data sensor yang ditampilkan pada aplikasi yang terpasang pada smartphone dapat dilihat secara real time.

\section{REFERENSI}

[1] a. wiyanto, "otomasisasi alat penyemprot tanaman anggrek otomatis berdasarkan kondisi suhu dan kelembaban," p-ISSN: 1978-5232; e-ISSN: 2527 -337, vol. 12, p. 8, 2018.

[2] h. w. wijaya, "perancangan alat penyiraman tanaman otomatisdengan yl69 berbasis arduinouno R3," yogyakarta, 2017.

[3] m. abdullah,, "sistem pemberian nutrisi dan penyiraman otomatis dengan sensor kelembaban tanah berbasis atmega328," ISSSN 2580-6661, vol. 2, p. 7, 2017.

[4] s. r. d. h. Sukartini, "pengaruh vitamin B dan Benziladenin terhadap pertumbuhan bibit anggrek Phalaenopsis hasil kultur jaringan," ISSN 2337-4993, vol. 2, p. 7, 2014.

[5] e. m. surtinah, "frekuensi pemberian Grow Quick LB terhadap pertumbuhan bibit anggrek dendrobium pada stadia komunitas pot," vol. 10, p. 10, 2013. 
